\title{
DYNAMIC MODELING OF LITHIUM-ION BATTERY WITH TEMPERATURE EFFECT
}

\author{
Yusuf MURATOĞLU, Alkan ALKAYA * \\ Mersin University, Mersin, Turkey \\ *Corresponding author; E-mail: alkanalkaya@ mersin.edu.tr \\ Received: 12 October 2016; Accepted: 25 February 2017
}

\begin{abstract}
Lithium ion (Li-ion) batteries have become a promising alternative power source in electric vehicles (EVs) due to their high nominal cell voltage, high energy density, long life and not having a memory effect. However temperature effect and dynamic characteristic of the li-ion batteries greatly affects their performance. In this study, a dynamic model of li-ion battery has been developed by MATLAB/Simulink and simulated at different temperatures. Simulink model contains dynamic circuit parameters as a function of state of charge and temperature effect. Simulation results show that proposed dynamic model is effective and operational under the different temperature rates for dynamic output characteristic of li-ion battery.
\end{abstract}

Key words: "Li-ion battery", "dynamic battery model", "temperature effect"

\section{Introduction}

Lithium ion batteries are widely used in EVs with high energy density, high nominal cell voltage, long life among the various rechargeable batteries such as Lead-Acid batteries, Ni-based batteries and Na-based batteries [1,2]. Li-ion batteries cannot be used without battery management system (BMS) in EVs because of their safety, reliability and performance. BMS include several features such as cell measurement, cell balancing, thermal measurement, safety and reliability [3]. Performance of the li-ion battery related with predict state of charge (SoC) which is a key component of the BMS accurately. The SoC of a battery is defined as a ratio of the remaining capacity and maximum available capacity of a battery and cannot be measured directly. Therefore, SoC should be estimated by using the measured signals such as voltage and current via accurate battery model $[4,5]$.

Several methods used for modelling of the lithium-ion battery in the literature [6-8]. These methods consist of four main groups such as analytical (experimental), statistical, electrochemical and electrical circuit models [9]. Analytical models based on developing physical model of the system with the help of physical equations and determine of model parameters with experimental results are simple and quick method. However, accuracy performance of the model is low [10]. Statistical model which is achieved model parameters by creating significant structures from data samples is a quick method with low accuracy. Electrochemical model based on the operation of the internal chemical structure of the battery is a complex method. Therefore, this method is hardly used [11]. Electrical circuit model, which enables mathematical operations on the equivalent circuit model is the most widely used method [12]. The electrical circuit models mainly include Thevenin model, PNGV 
(Partnership for a New Generation of Vehicles) model, NREL (National Renewable Energy Laboratory) model, Randles model [13].

While modelling the li-ion battery, it is essential to consider temperature effect because the ambient temperature and the cell temperature are both greatly affects the behavior of the battery. Several modelling techniques have been proposed to represent the temperature effect of the battery. In reference [14], proposed a battery model which is able to simulate the effects on the battery behavior made by temperature. In reference [15], temperature-dependent cell model is presented to improve state of charge estimation. Temperature effect has become attractive research area topic for battery modelling in electric vehicle field.

In this study, a dynamic model of li-ion battery has been developed with second order Thevenin model by MATLAB/Simulink. Simulink model contains capacity-resistance change effect according to state of charge and ambient temperature effect for dynamic characteristic of the li-ion battery. Proposed dynamic battery model simulated under different temperature conditions.

\section{Equivalent Circuit Model}

In this section, Second order Thevenin model shown in Fig. 1 is developed as the equivalent circuit model of the lithium-ion battery due to its high model accuracy and low complexity.

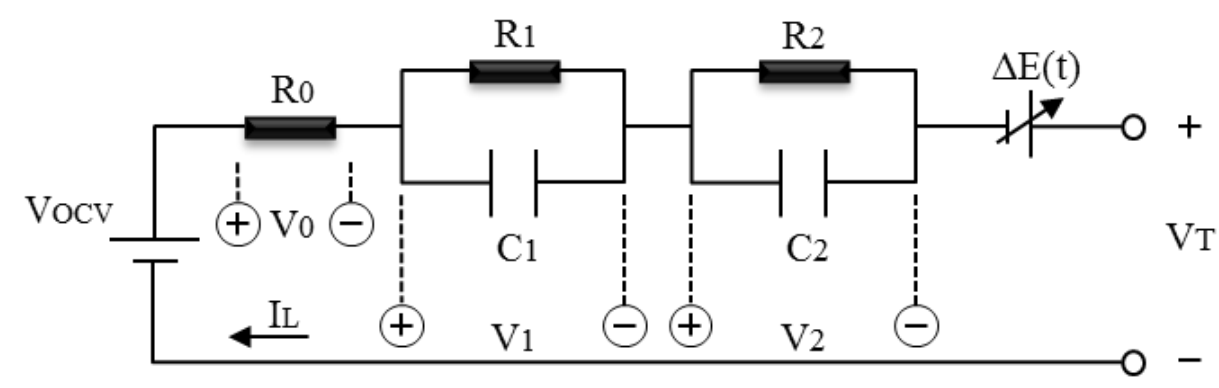

\section{Figure 1. Second order Thevenin equivalent circuit model.}

The equivalent circuit model can be described by following equations:

$$
\begin{gathered}
V_{T}=V_{O C V}-V_{1}-V_{2}-V_{0}+\Delta E(t) \\
V_{0}=R_{0} I_{L} \\
C_{1} \frac{d V_{1}}{d t}=-\frac{V_{1}}{R_{1}}+I_{L} \\
C_{2} \frac{d V_{2}}{d t}=-\frac{V_{2}}{R_{2}}+I_{L}
\end{gathered}
$$

where $R_{0}$ is the ohmic resistance, $R_{1}$ and $R_{2}$ are the polarization resistance, $C_{1}$ and $C_{2}$ are the polarization capacitance, $V_{1}$ and $V_{2}$ are the polarization voltages, $V_{T}$ is the terminal voltage, $V_{O C V}$ is the open circuit voltage, $\Delta E(t)$ is the potential correction term and $I_{L}$ is the load current.

\section{Open Circuit Voltage}

The general equation of the state of charge is expressed as follows: 


$$
S o C=S o C_{0}-\eta \int_{0}^{t} i(\tau) d \tau
$$

Where $\eta=1 /(3600 C), S o C$ is the present state of charge, $S o C_{0}$ is the initial state of charge and $C$ is the maximum available capacity. The open circuit voltage which is defined as electrical potential difference between the two terminal at the battery when it is disconnected from the electrical load has a non-linear relationship between the state of charge.

\section{Equivalent Circuit Parameters}

The dynamic parameter values of the equivalent circuit model and state of charge has a nonlinear relationship. In this nonlinear relationship, parameters of the equivalent circuit model have constant values at $20 \%-100 \%$ SoCs. However, parameters of the equivalent circuit model change rapidly due to the chemical reaction in the battery at 0\%-20\% SoCs. Dynamic parameters of the equivalent circuit model which is related with SoC defined as;

$$
\begin{aligned}
& R_{0}=k_{1} \times e^{k_{2} \times S O C}+k_{3} \\
& R_{1}=k_{4} \times e^{k_{5} \times S O C}+k_{6} \\
& C_{1}=k_{7} \times e^{k_{8} \times S O C}+k_{9} \\
& R_{2}=k_{10} \times e^{k_{11} \times S O C}+k_{12} \\
& C_{2}=k_{13} \times e^{k_{14} \times S O C}+k_{15}
\end{aligned}
$$

where $k_{1}, k_{2}, \ldots, k_{15}$ are constant values of the equivalent circuit parameters.

\section{Simulation Results}

MATLAB/Simulink is used to developed dynamic model of the li-ion battery. Proposed battery model contains $V_{O C V}-S o C$ block, equivalent circuit block, equivalent circuit parameters block and temperature effect block as shown in Fig. 2.

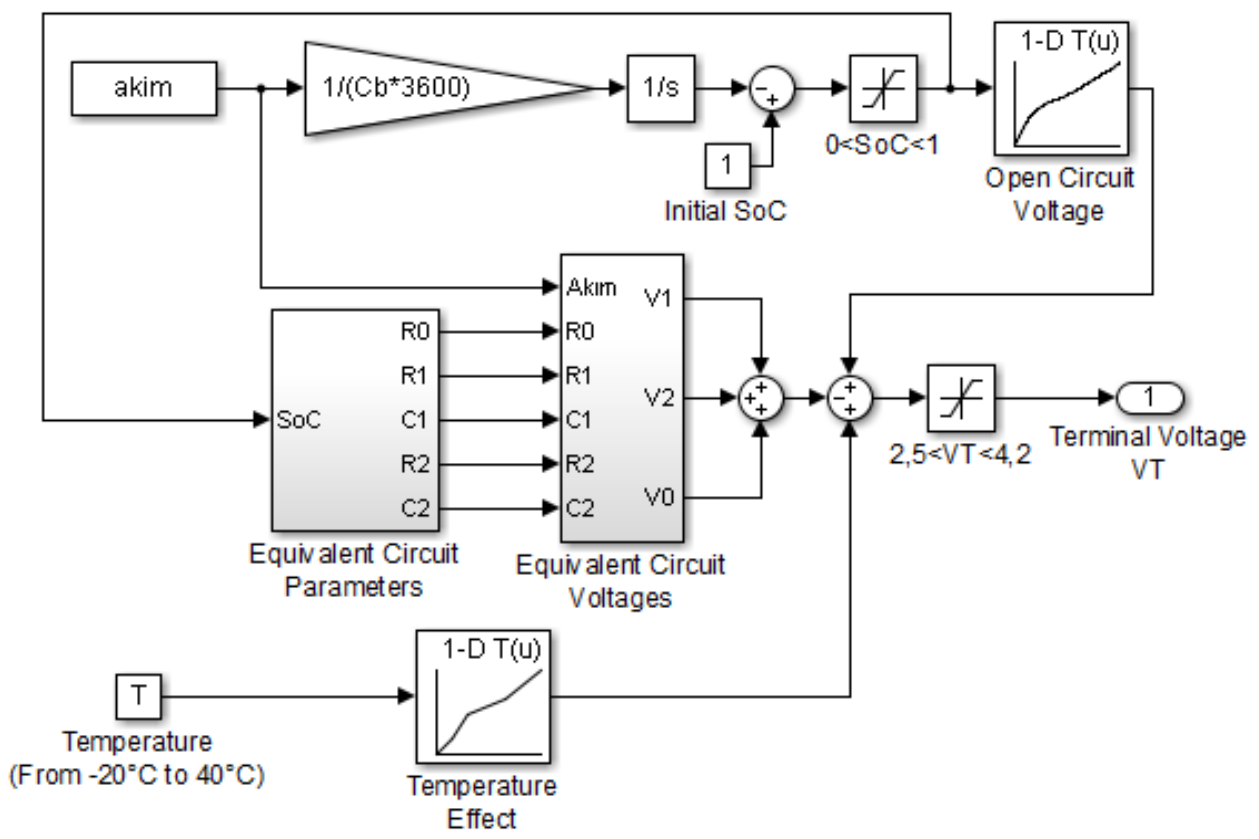

Figure 2. Dynamic Simulink model of li-ion battery. 
The change in temperature, affects the equilibrium potential. To compensate this temperature influence, $\Delta E(t)$ is used in Simulink model as potential correction term. Fig. 3 shows that change of $\Delta E(t)$ due to temperature can be found in Ref. [16]. Temperature effect block developed using Fig. 3 as a look-up table.

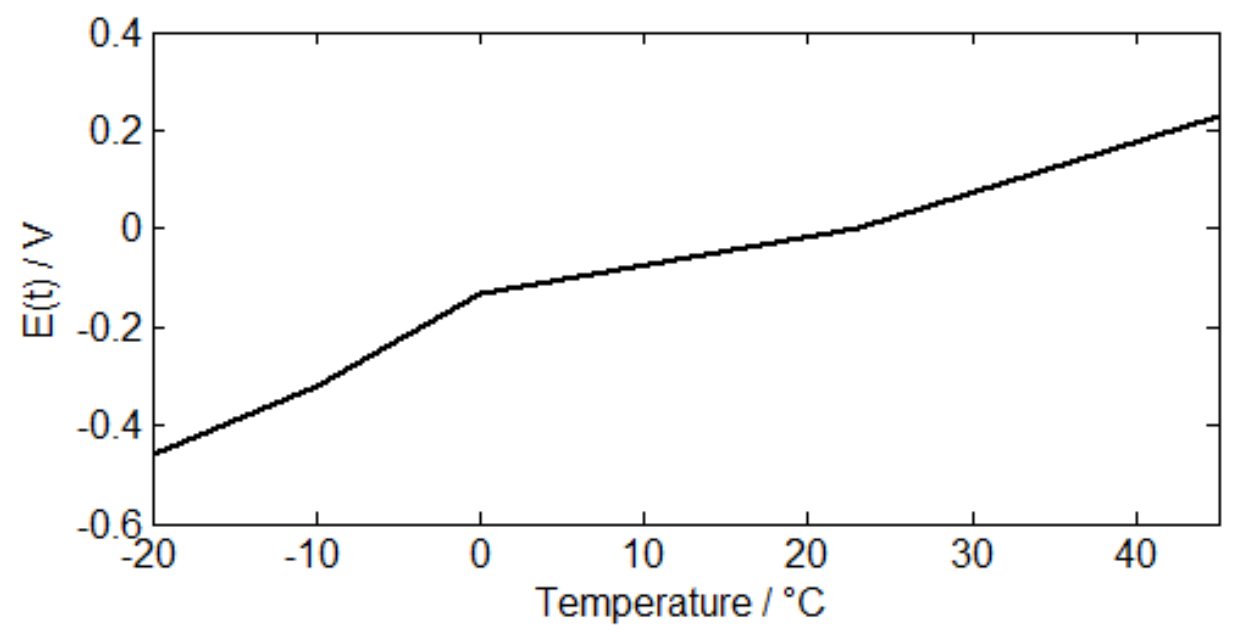

Figure 3. Temperature-dependent potential-correction term for the lithium-ion.

Fig. 4 shows the non-linear relationship between the $V_{O C V}$ and $S o C$. Open circuit voltage of the battery as a function of $\mathrm{SoC}$ is assumed as a seventh-order polynomial equation. It can be represented as:

$$
\begin{aligned}
& f\left(V_{O C V}, S o C\right)=66.235 \times S o C^{7}-242.73 \times S o C^{6}+364.5 \times S o C^{5} \\
& -291 \times S o C^{4}+134.7 \times S o C^{3}-37.016 \times S o C^{2}+6.4617 \times S o C+2.9007
\end{aligned}
$$

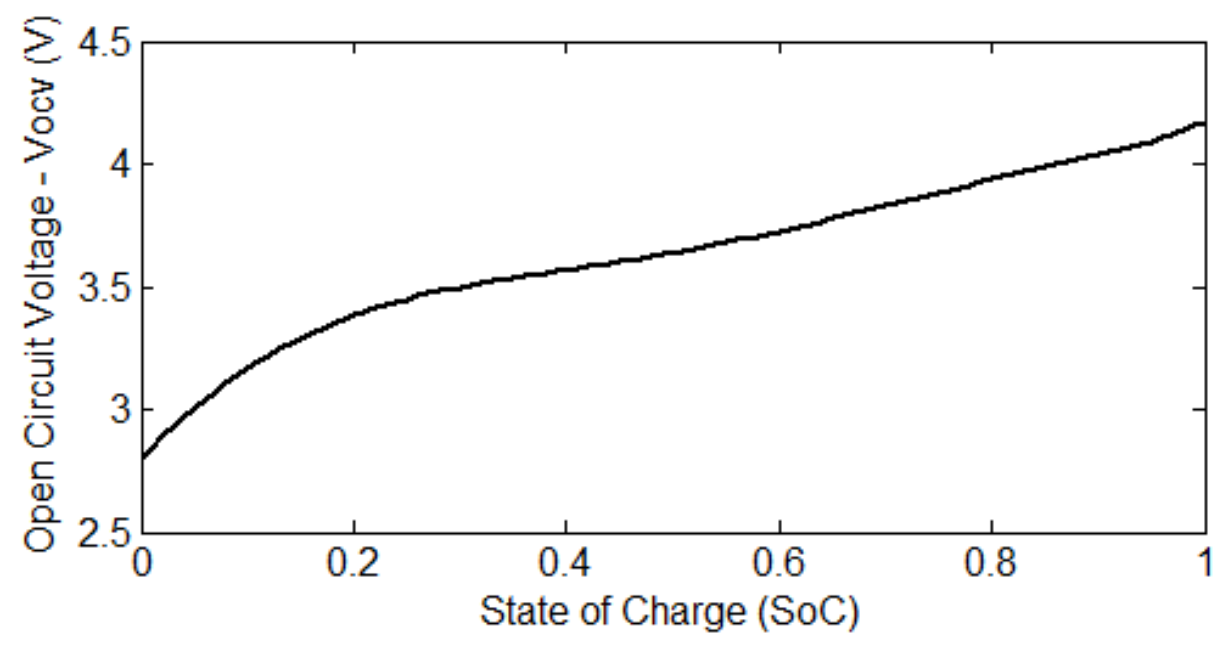

Figure 4. Non-linear relationship between open circuit voltage and state of charge.

Equivalent circuit block developed using Equations (1)-(4). Dynamic parameters of the equivalent circuit model which is related with $\mathrm{SoC}$ in equivalent circuit parameters block defined as; 


$$
\begin{gathered}
R_{0}=2,2236 \times e^{-33,8871 \times S o C}+0,016 \\
R_{1}=0,000124 \times e^{-25,0869 \times S o C}+0,1656 \\
C_{1}=732,6083 \times e^{-11,6207 \times S o C}+690,5780 \\
R_{2}=44,6259 \times e^{-333,6240 \times S o C}+0,0257 \\
C_{2}=6191,5 \times e^{-10,6698 \times S o C}+4470,1
\end{gathered}
$$

Proposed battery model is tested using $0.2 \mathrm{C}(0.65 \mathrm{~A})$ discharge test data with different temperature condition such as $-20^{\circ} \mathrm{C},-10^{\circ} \mathrm{C}, 0^{\circ} \mathrm{C}, 10^{\circ} \mathrm{C}, 20^{\circ} \mathrm{C}$ and $40^{\circ} \mathrm{C}$. Fig. 5 displays the change of terminal voltage for dynamic battery model with different temperature effect.

The change in temperature has deeply affected terminal voltage. The terminal voltage and the temperature affect each other negatively. When the temperature increases, the terminal voltage is decrease as shown in Fig. 5.

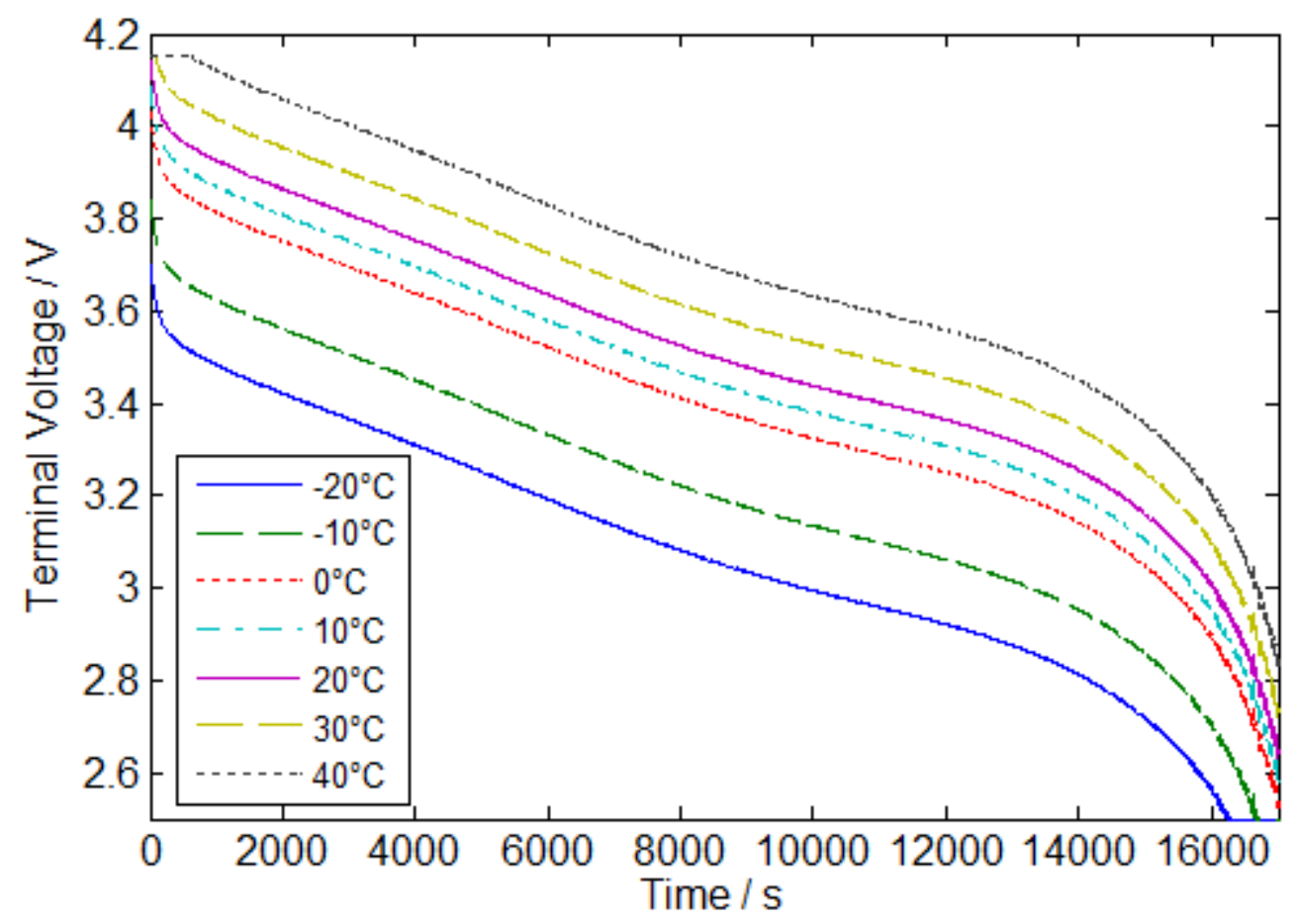

Figure 5. The change in battery runtime for a $0.65 \mathrm{~A}$ discharging condition at different temperatures.

\section{Conclusion}

In this study, dynamic battery model including capacity-resistance change effect at dynamic characteristic of the li-ion battery is proposed. Dynamic battery model developed by MATLAB/Simulink is tested using $0.2 \mathrm{C}(0.65 \mathrm{~A})$ discharge test data and different temperature effects at $-20^{\circ} \mathrm{C},-10^{\circ} \mathrm{C}, 0^{\circ} \mathrm{C}, 10^{\circ} \mathrm{C}, 20^{\circ} \mathrm{C}$ and $40^{\circ} \mathrm{C}$. Simulation results show that developed temperature depended dynamic model can reflect the output characteristic of li-ion battery effectively. 


\section{Acknowledgment}

The authors would like to thank for the financial support by scientific research project unit of Mersin University (Project number: BAP-2015-TP2-1196).

\section{References}

[1] Wang, Q., et al., A critical review of thermal management models and solutions of lithium-ion batteries for the development of pure electric vehicles, Renewable and Sustainable Energy Reviews, 64 (2016), pp. 106-128.

[2] Abada, S., et al., Safety focused modeling of lithium-ion batteries: A review, Journal of Power Sources, 306 (2016), pp. 178-192

[3] Rahimi-Eichi, H., et al., Sensitivity analysis of lithium-ion battery model to battery parameters, In Industrial Electronics Society, IECON 2013-39th Annual Conference of the IEEE, (2013), pp. 6794-6799

[4] Xiong, R., et al., Evaluation on state of charge estimation of batteries with adaptive extended Kalman filter by experiment approach, IEEE Transactions on Vehicular Technology, 62 (2013), 1, pp. 108-117

[5] He, Y., et al., A new model for State-of-Charge (SOC) estimation for high-power Li-ion batteries, Applied Energy, 101 (2013), pp. 808-814

[6] Wijewardana, S., et al., Dynamic battery cell model and state of charge estimation, Journal of Power Sources, 308 (2016), pp. 109-120

[7] Rahman, M. A., et al., Electrochemical model parameter identification of a lithium-ion battery using particle swarm optimization method, Journal of Power Sources, 307 (2016), pp. 86-97

[8] Rao, R., et al., Battery modeling for energy aware system design, Computer, 36 (2003), 12, pp. $77-87$

[9] Fotouhi, A., et al., A review on electric vehicle battery modelling: From Lithium-ion toward Lithium-Sulphur, Renewable and Sustainable Energy Reviews, 56 (2016), pp. 1008-1021

[10] Rong, P., Pedram, M., An analytical model for predicting the remaining battery capacity of lithium-ion batteries, IEEE Transactions on Very Large Scale Integration (VLSI) Systems, 14 (2006), 5, pp. 441-451

[11] Krintz, C., et al., Application-level prediction of battery dissipation. In Proceedings of the 2004 international symposium on Low power electronics and design,(2004), pp. 224-229

[12] Bae, K. C., et al., LiFePO4 dynamic battery modeling for battery simulator, In Industrial Technology (ICIT), 2014 IEEE International Conference on, (2014), pp. 354-358

[13] He, H., et al., Evaluation of lithium-ion battery equivalent circuit models for state of charge estimation by an experimental approach, Energies, 4 (2011), 4, pp. 582-598 
[14] Tan, Y. K., et al., Modelling of battery temperature effect on electrical characteristics of Liion battery in hybrid electric vehicle, In Power Electronics and Drive Systems (PEDS), 2011 IEEE Ninth International Conference on, (2011), pp. 637-642

[15] Baronti, F., et al., State-of-charge estimation enhancing of lithium batteries through a temperature-dependent cell model, In Applied Electronics (AE), 2011 International Conference on, (2011), pp. 1-5

[16] Gao, L., et al., Dynamic lithium-ion battery model for system simulation, IEEE transactions on components and packaging technologies, 25, (2002), 3, pp. 495-505 